\title{
Prospective evaluation of anxiety, pain, and embarrassment associated with cystoscopy and urodynamic testing in clinical practice
}

\author{
Xavier Biardeau, MD; Ornella Lam, MD; Van Ba, MD; Lysanne Campeau, MD; Jacques Corcos, MD \\ Department of Urology, Jewish General Hospital, McGill University, Montreal, QC, Canada
}

Cite as: Can Urol Assoc J 2017;11 (3-4):104-10. http://dx.doi.org/10.5489/cuaj.4127

Supplementary data available at www.cuaj.ca

See related commentary on page 111.

\section{Abstract}

Introduction: We sought to prospectively assess anxiety, pain, and embarrassment associated with diagnostic cystoscopy and multichannel urodynamic study (UDS).

Methods: All consecutive patients undergoing diagnostic cystoscopy or UDS in our department over a period of nine months were asked to participate. Two anonymous auto-administered questionnaires were specifically designed to collect basic epidemiological data, document medical history, and assess the quality of information provided, along with prevalence and level (0-10 numerical visual analog rating scale) of anxiety, pain, and embarrassment experienced before and/or during the procedures. Statistical analysis was carried out to identify underlying factors that could have influenced patients' experience and ascertain potential correlations between anxiety, pain, and embarrassment.

Results: 101 and 185 patients were respectively evaluated immediately after cystoscopy and UDS. Multivariate analysis repeatedly showed statistical correlations between anxiety, pain, and embarrassment, with regard to prevalence and level of intensity in both cystoscopy and UDS populations. Males and young patients were more likely to present anxiety, pain, or embarrassment during cystoscopy and UDS. Interestingly, patients who reported having received complete information before cystoscopy were significantly more likely to experience anxiety $(62.6 \%$ vs. $20.0 \%$; $p=0.009)$.

Conclusions: The present study demonstrated the major impact of gender and age on patients' experience. Interestingly, information provided before cystoscopy was reported to have a negative impact on patients' perception of anxiety; this could be partly prevented by optimizing the way information is provided to patients.

\section{Introduction}

Cystoscopy and multichannel urodynamic study (UDS) are essential and valuable diagnostic tools in our daily urological practice. Cystoscopy is part of the evaluation process in patients complaining of lower urinary tract symptoms (LUTS) and is undertaken repeatedly in patients being monitored for non-invasive bladder tumours. This procedure allows direct visual examination of the bladder cavity and wall to detect abnormalities, such as diverticula, stones, inflammation, and tumours. UDS is usually performed in patients complaining of LUTS or presenting neurological diseases suspected to impact the bladder-sphincter system. The procedure aims to diagnose lower urinary tract disorders through continuous measurement of abdominal, bladder, and urethral pressures during the filling and voiding phases. Despite their invasive nature, as recognized by the urological community, comprehensive evaluations of patients' experience during cystoscopy ${ }^{1-5}$ and $\mathrm{UDS}^{6-9}$ are scarcely reported in the literature.

We prospectively assessed anxiety, pain, and embarrassment associated with such procedures and investigated factors that could potentially influence them to find potential ways of improving general tolerance during these examinations.

\section{Methods}

\section{Patients}

The present study was approved by our hospital research ethics committee. All consecutive patients with preserved urethral and bladder sensation referred by the two lead authors over a period of nine months for diagnostic cystoscopy or UDS were systematically asked to participate. A specific information form and an anonymous auto-administered questionnaire were given to them at the reception office. Patients who agreed to participate completed the questionnaire after the procedures and left them in a box placed at the waiting room exit.

\section{Procedures}

\section{Cystoscopy}

All procedures were performed in an outpatient setting by urologists assisted by dedicated nurses. During their initial consultation, patients received an information pamphlet produced 
by the Canadian Urological Association (CUA) detailing the procedures. Men were placed in a standard decubitus position while women were placed in a dorsolithotomy position. Flexible $(16 \mathrm{Fr})$ or rigid $\left(17 \mathrm{Fr}, 70^{\circ}\right)$ cystoscopes were used in men and women, respectively. No topical urethral anesthesia was administered in our patient cohort, as in our routine practice. Cystoscopes were inserted in the urethra under direct vision for systematic exploration of the entire bladder cavity.

\section{UDS}

All UDSs were performed in an outpatient setting by trained, dedicated nurses. During their initial consultation, patients received a CUA-produced information pamphlet detailing the procedure. Free uroflowmetry was followed by clean catheterization (male $16 \mathrm{Fr}$, female $14 \mathrm{Fr}$ ). Both men and women were placed in a dorsolithotomy position for the insertion of recording transducers and then seated for the remainder of the study. The urethral catheter (dual lumen $7 \mathrm{Fr}$, Laborie Medical ULC, Mississauga, ON, Canada) was introduced first, after application of a non-anesthetic lubricating gel, and two electrodes (Neotrode ${ }^{\circledR}$ II, ConMed Corporation, Utica, NY, U.S.) were positioned close to the anal area, at three hours and nine hours, respectively. The rectal catheter (abdominal pressure $9 \mathrm{Fr}$, Laborie Medical ULC) was then introduced into the rectum, and the balloon was filled with 3 cc of water. A room-temperature saline solution was infused at a constant rate of $50 \mathrm{cc} /$ minute with an Aquarius II UDS station (Laborie Medical ULC). Cystometrograms, Valsalva leak point pressure (VLPP), pressure flow study with electromyogram (EMG) and post-void residual (PVR) were recorded, tailored to the reason for the test. To assess VLPP, the bladder was filled a second time until the first sensation of bladderfilling occurred. The urethral catheter was removed and the patient was asked to strain in seated and standing positions. The electrodes and rectal catheter were finally removed at the end of the procedure.

\section{Questionnaires}

Two anonymous, auto-administered questionnaires, specifically developed in our department, were built with different types of responses, including open answers, multiple-choice questions, and 0-10 numerical rating scales (NRS). They were available in both English and French, depending on patient preference. Each was designed to successively collect basic epidemiological data and medical history, evaluating the quality of information provided, and assessing the prevalence and level of anxiety, pain, and embarrassment experienced before and/or during the procedures. The questionnaires were considered for final analysis only if completed in their entirety.

\section{Statistical analysis}

Descriptive results were reported as absolute values (n) and percentages (\%) for categorical variables and as mean \pm standard deviation (SD) for discrete variables. Statistical analysis was built to identify underlying factors that could have influenced anxiety, pain, and/or embarrassment, including gender, age, repeat procedures, and quality of information provided, as well as correlations between anxiety, pain, and embarrassment. Univariate analyses with the two-sided Mann-Whitney $U$ test (discrete variables, two groups), the Kruskall-Wallis test (discrete variables, $>2$ groups), and Fisher's exact test (categorical variables) were conducted with IBM SPPS statistics, version 21.0 (IBM Corporation, Armonk, NY, U.S.). Multivariate analyses were finally performed with multiple linear models. The prevalence of anxiety, pain, and embarrassment, as well as related levels of intensity, were successively considered as dependent variables, and only independent variables associated with $p<0.3$ in univariate analysis were tested. Statistical significance was set at $p<0.05$.

\section{Results}

\section{Patients' characteristics (Table 1)}

In total, 101 patients were included in cystoscopy analysis. Ninety-one patients $(90.1 \%)$ said they had received complete information regarding diagnostic cystoscopy before the procedure, and $98(97.0 \%)$ accepted to subsequently undergo repeat cystoscopy if medically indicated. Females were significantly more likely to undergo a first cystoscopy at questionnaire time $(45.7 \%$ vs. $16.7 \% ; \mathrm{p}=0.004)$.

A total of 185 patients were included in UDS analysis. Males had significantly higher mean body mass index than females (29.5 vs. 26.9; p<0.001). Overall, 113 patients $(61.1 \%)$ said they had received complete information on UDS before the procedure, and 172 patients (93.0\%) accepted repeat UDS if needed.

\section{Anxiety (Table 2)}

Multivariate analysis showed that anxiety, pain, and embarrassment were statistically correlated with each other during cystoscopy and UDS (Supplementary Table 1; available at www.cuaj.ca). Fifty-nine patients (58.4\%) reported having experienced a certain degree of anxiety before cystoscopy, with a mean anxiety level of $2.8 \pm 3.0$. Multivariate analysis of the cystoscopy group revealed that the percentage of patients reporting anxiety was significantly higher in younger patients ( $18-50$ years old) $(93.7 \%$ vs. $51.8 \%$; $p=0.045)$, as well as in patients who received information beforehand 
Biardeau et al.

\begin{tabular}{|c|c|c|c|c|}
\hline \multicolumn{5}{|l|}{ Cystoscopy - Patient characteristics } \\
\hline & $\begin{array}{l}\text { Overall } \\
n=101\end{array}$ & $\begin{array}{c}\text { Males } \\
\mathrm{n}=66\end{array}$ & $\begin{array}{c}\text { Females } \\
\mathrm{n}=35\end{array}$ & $\mathbf{p}$ \\
\hline Age, mean $\pm S D$ & $64 \pm 14.4$ & $66 \pm 15.2$ & $61 \pm 12.2$ & 0.034 \\
\hline BMI mean \pm SD & $26 \pm 4.9$ & $27 \pm 5.1$ & $26 \pm 4.6$ & 0.220 \\
\hline First-time cystoscopy, n (\%) & $27(26.7)$ & $11(16.7)$ & $16(45.7)$ & 0.004 \\
\hline \multicolumn{5}{|l|}{ Symptoms, n (\%) } \\
\hline Overactive bladder & $17(16.8)$ & $7(15.2)$ & $10(28.6)$ & 0.028 \\
\hline Urge incontinence & $11(10.9)$ & $4(6.1)$ & $7(20.0)$ & 0.045 \\
\hline Recurrent UTI & $13(12.9)$ & $6(9.1)$ & $7(20.0)$ & 0.132 \\
\hline Bladder pain & $3(3.0)$ & $0(0.0)$ & $3(8.6)$ & 0.039 \\
\hline Hematuria & $34(33.7)$ & $23(34.8)$ & $11(31.4)$ & 0.826 \\
\hline Followup & $21(20.8)$ & $15(22.7)$ & $6(17.1)$ & 0.611 \\
\hline Other & $16(15.8)$ & $13(19.7)$ & $3(8.6)$ & 0.166 \\
\hline Information, ${ }^{*} \mathrm{n}(\%)$ & $91(90.1)$ & $61(92.4)$ & $30(85.7)$ & 0.309 \\
\hline $\begin{array}{l}\text { Willing to undergo another } \\
\text { cystoscopy, } \mathrm{n}(\%)\end{array}$ & $98(97.0)$ & $64(96.9)$ & $34(97.1)$ & 1.000 \\
\hline \multicolumn{5}{|l|}{ UDS - Patient characteristics } \\
\hline & $\begin{array}{l}\text { Overall } \\
n=185\end{array}$ & $\begin{array}{c}\text { Males } \\
\mathrm{n}=68\end{array}$ & $\begin{array}{c}\text { Females } \\
\mathrm{n}=117\end{array}$ & $\mathbf{p}$ \\
\hline Age, mean \pm SD & $57.9 \pm 15.4$ & $61.2 \pm 15.1$ & $56.0 \pm 15.2$ & 0.073 \\
\hline $\mathrm{BMI}$, mean $\pm \mathrm{SD}$ & $27.8 \pm 7.9$ & $29.5 \pm 6.1$ & $26.9 \pm 8.7$ & $<0.001$ \\
\hline First-time UDS, n (\%) & $130(70.3)$ & $46(67.6)$ & $84(71.8)$ & 0.618 \\
\hline \multicolumn{5}{|l|}{ Symptoms, n (\%) } \\
\hline Overactive bladder & $85(45.9)$ & $28(41.2)$ & $57(48.7)$ & 0.360 \\
\hline Urge incontinence & $44(23.8)$ & $13(19.2)$ & $31(26.5)$ & 0.287 \\
\hline Stress incontinence & $62(33.5)$ & $15(22.1)$ & $47(40.2)$ & 0.015 \\
\hline Urinary retention & $25(13.0)$ & $16(23.5)$ & $9(7.7)$ & 0.003 \\
\hline Bladder pain & $27(14.6)$ & $6(8.8)$ & $21(17.9)$ & 0.130 \\
\hline Followup & $21(11.4)$ & $8(11.8)$ & $13(11.1)$ & 1.000 \\
\hline Other & $15(8.1)$ & $5(7.4)$ & $10(8.5)$ & 1.000 \\
\hline Information, ${ }^{*} \mathrm{n}(\%)$ & $113(61.1)$ & $43(63.2)$ & $70(59.8)$ & 0.755 \\
\hline $\begin{array}{l}\text { Willing to undergo another UDS, } \\
\mathrm{n}(\%)\end{array}$ & $172(93.0)$ & $62(91.2)$ & $110(94.0)$ & 0.554 \\
\hline
\end{tabular}

*Patients reported having received information before the procedure. BMI: body mass index; SD: standard deviation; UDS: urodynamic study; UTI: urinary tract infection. be correlated with pain experience $(\mathrm{p}<0.001)$ (Supplementary Table 2; available at www.cuaj.ca). Pain level at the time of examination table installation was significantly higher in patients undergoing repeat UDS (1.0 vs. $0.5 ; p=0.014$ ), while pain level at the time of micturition was significantly higher in males (1.9 vs. $1.0 ; \mathrm{p}<0.001)$ and younger patients (18-60 years old) (2.0 vs. $0.7 ; p=0.043$ ).

\section{Embarrassment (Table 4)}

Twenty-two patients (21.8\%) reported that they experienced embarrassment during cystoscopy, with mean embarrassment levels of $1.0 \pm 2.5$, $0.9 \pm 2.3$, and $0.1 \pm 1.1$ at examination table installation, cystoscope introduction, and removal, respectively. On multivariate analysis (Supplementary Table 1; available at www.cuaj.ca), embarrassment was significantly more frequent in younger patients during cystoscopy $(43.7 \%$ vs. $17.6 \% ; p=0.026)$. Sixtyfour patients $(34.6 \%)$ experienced embarrassment during UDS, with mean embarrassment levels of 0.8 $\pm 2.0,1.6 \pm 2.8,1.4 \pm 2.6$, and 1.2 \pm 2.6 at examination table installation, urethral catheter insertion, rectal catheter insertion, and micturition, respectively.
(62.6\% vs. $20.0 \%$; $p=0.009)$. Seventy-seven patients (41.6\%) reported anxiety before UDS, with mean anxiety level of $2.2 \pm 3.1$.

\section{Pain (Table 3)}

Sixty patients (59.4\%) reported pain during cystoscopy, with mean pain levels of $0.7 \pm 2.1,2.8 \pm 3.1$, and $1.4 \pm 2.6$ at the time of examination table installation, cystoscope insertion, and removal, respectively. One hundred eleven patients $(60.0 \%)$ experienced pain during UDS, with mean pain levels of $0.7 \pm 1.8,3.0 \pm 3.1,1.4 \pm 2.2$, and $1.3 \pm 2.2$ at examination table installation, urethral catheter insertion, rectal catheter insertion, and micturition, respectively. On multivariate analysis, males $(73.5 \%$ vs. $52.1 \%$; $\mathrm{p}=0.004)$ were significantly more likely to report pain during UDS, and age was found to

\section{Discussion}

The present study discerned good overall tolerance of invasive urological diagnostic procedures, with $97.0 \%$ and $93.0 \%$ of patients willing to undergo repeat cystoscopy or UDS if medically indicated. These results are in accordance with previous publications. Anxiety, pain, and embarrassment reported before and during these invasive diagnostic urological procedures were highly correlated. Such a tangle between apprehension, painful sensation, and discomfort has already been described in the literature, ${ }^{10,11}$ and several authors have demonstrated that patients systematically anticipated more pain than they actually experienced. ${ }^{3,5,12}$

In the present study, multivariate analysis divulged an increased proportion of patients with anxiety before cystoscopy in the younger population (18-50 years old). Such 


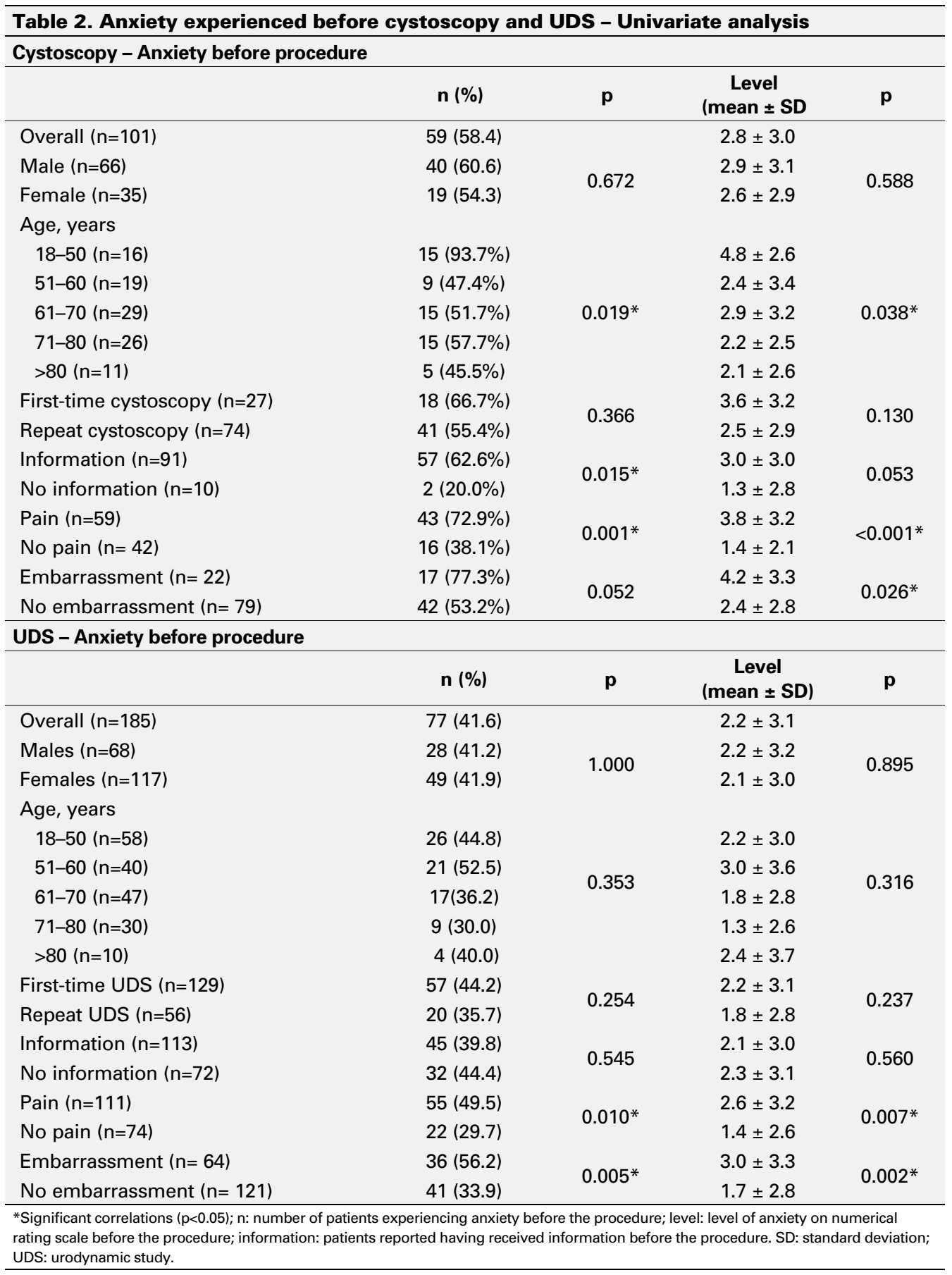

In the current literature, some factors have already been demonstrated to influence pain perception during cystoscopy, including gender, ${ }^{2}$ age, ${ }^{11}$ and, more controversially, history of previous procedure. ${ }^{2,5,13,14}$ In the present study, however, gender, age, and history of previous procedure were not statistically correlated with pain perception. We assume that the absence of differences between genders could be partly explained by cystoscope type (flexible in men vs. rigid in women). Regarding UDS, several authors have linked male gender $^{8}$ and young age ${ }^{6}$ with increased pain levels at UDS time (i.e, first vs. subsequent procedures). We reported similar results with multivariate analysis, observing that first-time UDS was statistically correlated with decreased pain level at examination table installation. As this pain reduction has more to do with apprehension than perception of a really painful sensation, we think that repeat UDSs can significantly increase anxiety.

Some authors reported, after univariate analysis, that women and young patients experienced significantly high embarrassment levels when undergoing cystoscopy or UDS. ${ }^{1,8}$ However, in the present study, multivariate analysis only demonstrated statistical correlation between

a correlation has already been demonstrated by Yiou et al in patients undergoing UDS. ${ }^{1}$ Furthermore, patients who received complete information before cystoscopy were more likely to experience anxiety. Although not reported previously, this is clearly supported by Greenstein et al, who evaluated the effect of routine explanation provided to men for their expectation of pain associated with UDS, and reported that explanation by a urologist significantly increased pain from a mean level of 4.2 to $5.17 . .^{12}$ age and embarrassment during cystoscopy.

Because anxiety, pain, and embarrassment associated with cystoscopy and UDS have been reported repeatedly to correlate with each other, , $^{3,-12}$ we presume they should logically be taken into account and prevented through an integrated and comprehensive approach. Many strategies have been studied to relieve pain during such procedures, particularly cystoscopy, including pain lubricants, topical anesthetics, ${ }^{15}$ flexible cystoscopes, pre-emptive non-steroidal 
Biardeau et al.

Table 3. Pain experienced during cystoscopy and UDS - Univariate analysis

Cystoscopy - Pain during procedure

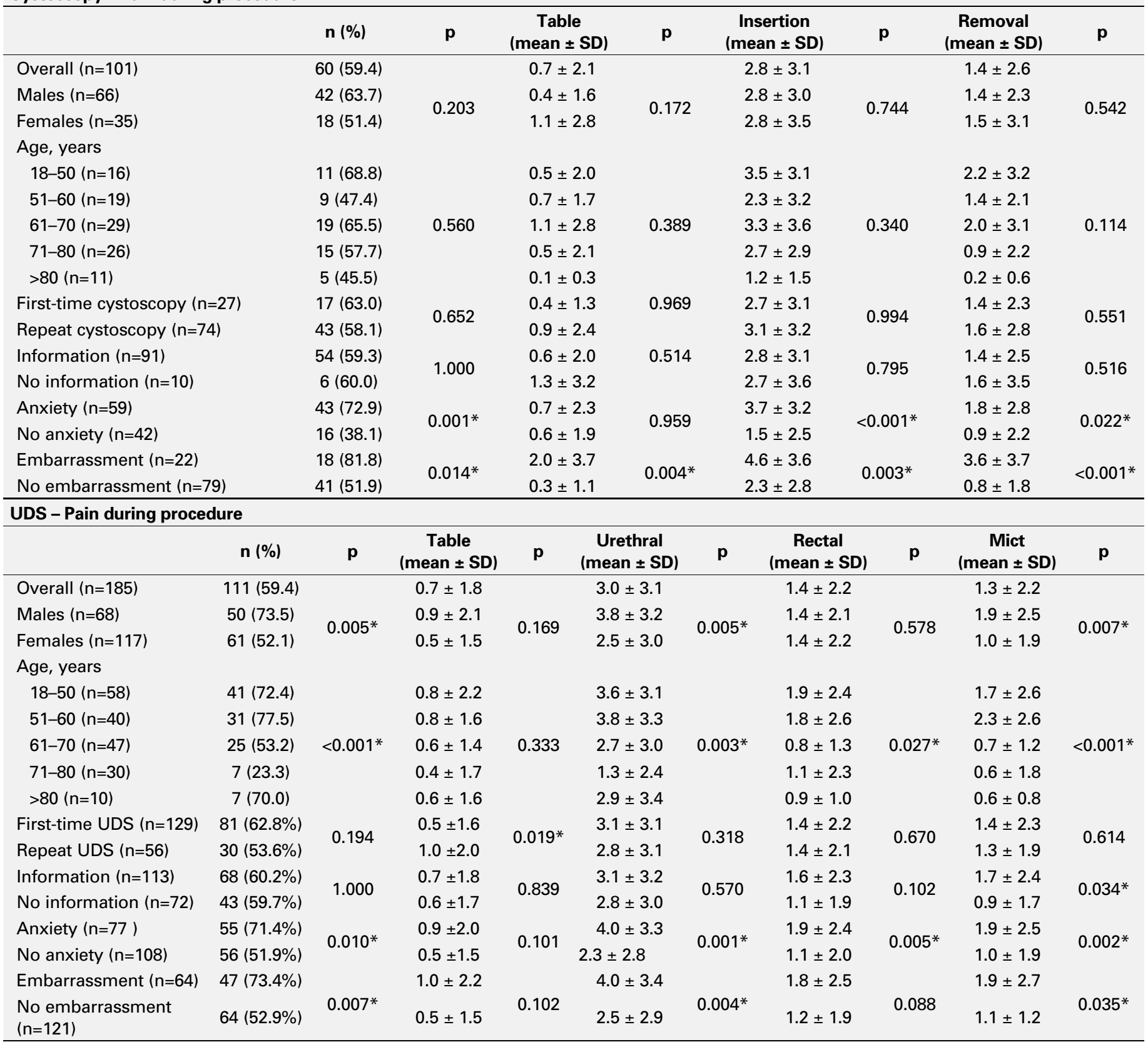

*Significant correlations $(\mathrm{p}<0.05)$; $\mathrm{n}$ : number and percentage of patients experiencing pain during the procedure; table: level of pain on numerical rating scale at the time of positioning on examination table; insertion: level of pain on numerical rating scale at the time of cystoscope insertion; removal: level of pain on numerical rating scale at the time of cystoscope removal;

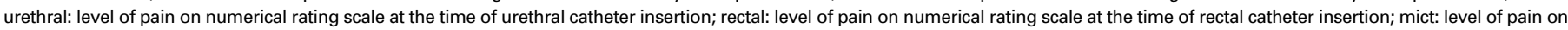
numerical rating scale at the time of micturition; information: patients reported having received information before the procedure. SD: standard deviation; UDS: urodynamic study.

anti-inflammatory drugs, ${ }^{16}$, nitrous oxide inhalation, ${ }^{17}$ high irrigation pressure regimens, ${ }^{18,19}$ relaxing music, ${ }^{20,21}$, realtime cystoscopy visualization, ${ }^{22-24}$ and even virtual reality distraction. ${ }^{25}$ However, more simply, we believe that the quality of medical information provided could play a major role in patient perceptions of anxiety, pain, or embarrassment and should be considered as a fundamental issue. Indeed, although comprehensive explanation of the pro- cedure is crucial, it has been demonstrated to significantly increase anxiety, ${ }^{12}$ and probably augments pain and embarrassment if not delivered optimally.

Type of vocabulary, such as avoiding pain-related words, ${ }^{26,27}$ clarity more than amount of information provided, ${ }^{28}$ and standard written information forms ${ }^{29}$ have been reported to decrease anxiety and/or pain during diverse invasive procedures. Furthermore, it has been proposed that 


\begin{tabular}{|c|c|c|c|c|c|c|c|c|c|c|c|}
\hline \multicolumn{12}{|c|}{ Cystoscopy - Embarrassment during procedure } \\
\hline & & g procedure & $\mathbf{p}$ & \multicolumn{2}{|c|}{$\begin{array}{c}\text { Table } \\
(\text { mean } \pm S D)\end{array}$} & $\mathbf{p}$ & \multicolumn{2}{|c|}{$\begin{array}{c}\text { Insertion } \\
\text { (mean } \pm \text { SD) }\end{array}$} & $\mathbf{p}$ & $\begin{array}{c}\text { Removal } \\
(\text { mean } \pm S D)\end{array}$ & p \\
\hline Overall $(n=101)$ & & $22(21.8 \%)$ & \multirow{3}{*}{1.000} & \multicolumn{2}{|c|}{$1.0 \pm 2.5$} & & \multicolumn{2}{|c|}{$0.9 \pm 2.3$} & \multirow{3}{*}{0.445} & $0.1 \pm 1.1$ & \multirow{3}{*}{0.636} \\
\hline Males $(n=66)$ & & $14(21.2 \%)$ & & \multirow{2}{*}{\multicolumn{2}{|c|}{$\begin{array}{l}0.9 \pm 2.2 \\
1.1 \pm 2.9\end{array}$}} & \multirow{2}{*}{0.680} & \multirow{2}{*}{\multicolumn{2}{|c|}{$\begin{array}{l}0.6 \pm 1.6 \\
1.5 \pm 3.2\end{array}$}} & & \multirow{2}{*}{$\begin{array}{l}0.1 \pm 0.5 \\
0.3 \pm 1.7\end{array}$} & \\
\hline Females $(n=35)$ & & $8(22.9 \%)$ & & & & & & & & & \\
\hline \multicolumn{12}{|l|}{ Age, years } \\
\hline $18-50(n=16)$ & & $7(43.7 \%)$ & \multirow{5}{*}{0.109} & \multicolumn{2}{|c|}{$1.4 \pm 2.3$} & \multicolumn{3}{|c|}{$1.5 \pm 2.7$} & \multicolumn{3}{|c|}{$0.3 \pm 1.0$} \\
\hline $51-60(n=19)$ & & $3(15.8 \%)$ & & \multicolumn{2}{|c|}{$0.6 \pm 1.9$} & & & $4 \pm 1.1$ & & $0.0 \pm 0.0$ & \\
\hline $61-70(n=29)$ & & $8(27.6 \%)$ & & $1.3 \pm$ & & 0.310 & & \pm 2.6 & 0.270 & $0.0 \pm 0.0$ & 0.540 \\
\hline $71-80(n=26)$ & & $3(11.5 \%)$ & & $0.8 \pm$ & & & & \pm 2.8 & & $0.4 \pm 2.0$ & \\
\hline$>80(n=11)$ & & $1(9.1 \%)$ & & $0.4 \pm$ & & & & $2 \pm 0.6$ & & $0.0 \pm 0.0$ & \\
\hline First-time cystoscopy ( & =27) & $8(29.6 \%)$ & & $1.4 \pm$ & & 0.198 & & \pm 2.2 & & $0.5 \pm 2.0$ & \\
\hline Repeat cystoscopy ( $n=7$ & & $14(18.9 \%)$ & 0.281 & $0.8 \pm$ & & & & $9 \pm 2.4$ & 0.408 & $0.0 \pm 0.0$ & 0.019 \\
\hline Information ( $\mathrm{n}=91$ ) & & $20(22.0 \%)$ & & $0.9 \pm$ & & $0.77 \varepsilon$ & & \pm 2.3 & & $0.2 \pm 1.1$ & \\
\hline No information $(n=10)$ & & $2(20.0 \%)$ & 1.000 & $1.4 \pm$ & & & & \pm 3.2 & 0.492 & $0.0 \pm 0.0$ & 0.638 \\
\hline Anxiety $(n=59)$ & & $17(28.8 \%)$ & & $1.2 \pm$ & & & & \pm 2.6 & & $1.4 \pm 0.2$ & \\
\hline No anxiety $(n=42)$ & & $5(11.9 \%)$ & 0.052 & $0.6 \pm$ & & 0.083 & & $5 \pm 1.8$ & $0.038^{*}$ & $0.0 \pm 0.0$ & 0.230 \\
\hline Pain $(n=59)$ & & $18(42.4 \%)$ & & $1.4 \pm$ & & & & $3 \pm 2.9$ & & $0.2 \pm 1.4$ & \\
\hline No pain $(n=42)$ & & $4(9.5 \%)$ & $0.014^{*}$ & $0.4 \pm$ & & 0.056 & & $3 \pm 1.0$ & $0.030^{*}$ & $0.0 \pm 0.0$ & 0.230 \\
\hline UDS - Embarrassment 0 & uring proced & dure & & & & & & & & & \\
\hline & n (\%) & $\mathbf{p}$ & $\begin{array}{c}\text { Table } \\
(\text { mean } \pm \text { SD })\end{array}$ & $\mathbf{p}$ & $\begin{array}{r}\text { Ure } \\
\text { Imean }\end{array}$ & $\begin{array}{l}\text { hral } \\
\pm \text { SD) }\end{array}$ & $\mathbf{p}$ & $\begin{array}{c}\text { Rectal } \\
(\text { mean } \pm \text { SD })\end{array}$ & ) & $\begin{array}{l}\text { Mict (mean } \\
\quad \pm \text { SD) }\end{array}$ & $\mathbf{p}$ \\
\hline Overall $(n=185)$ & $64(34.6 \%)$ & & $0.8 \pm 2.0$ & & 1.6 & 2.8 & & $1.4 \pm 2.6$ & & $1.2 \pm 2.6$ & \\
\hline Males $(\mathrm{n}=68)$ & $20(29.4 \%)$ & & $0.6 \pm 1.8$ & & 1.6 & & & $1.0 \pm 2.4$ & & $0.7 \pm 2.1$ & \\
\hline Females ( $n=117$ ) & $44(37.6 \%)$ & 0.268 & $0.9 \pm 2.1$ & 0.192 & 1.6 & & 0.544 & $1.6 \pm 2.6$ & 0.088 & $1.4 \pm 2.8$ & 0.068 \\
\hline Age, years & & & & & & & & & & & \\
\hline $18-50(n=58)$ & $20(34.5 \%)$ & & $0.8 \pm 2.2$ & & 1.8 & 3.0 & & $1.6 \pm 2.8$ & & $1.6 \pm 2.9$ & \\
\hline $51-60(n=40)$ & $15(37.5 \%)$ & & $1.1 \pm 2.5$ & & 2.0 & 3.3 & & $2.0 \pm 3.1$ & & $1.4 \pm 2.8$ & \\
\hline $61-70(n=47)$ & $14(29.8 \%)$ & 0.925 & $0.6 \pm 1.5$ & 0.868 & 1.3 & 2.3 & 0.721 & $0.9 \pm 2.0$ & 0.296 & $0.6 \pm 2.1$ & 0.108 \\
\hline $71-80(n=30)$ & $11(36.7 \%)$ & & $0.8 \pm 2.1$ & & 1.1 & 2.3 & & $1.0 \pm 2.2$ & & $0.9 \pm 2.5$ & \\
\hline$>80(n=10)$ & $4(40.0 \%)$ & & $0.4 \pm 1.3$ & & 1.3 & 3.2 & & $0.8 \pm 2.5$ & & $0.8 \pm 1.6$ & \\
\hline First-time UDS ( $n=129)$ & $46(35.7 \%)$ & & $0.9 \pm 2.2$ & & 1.7 & 3.0 & & $1.4 \pm 2.7$ & & $1.2 \pm 2.7$ & \\
\hline Repeat UDS ( $n=56)$ & $18(32.1 \%)$ & 0.612 & $0.6 \pm 1.5$ & 0.945 & 1.2 & & 0.453 & $1.1 \pm 2.2$ & 0.640 & $1.0 \pm 2.4$ & 0.948 \\
\hline Information ( $n=113$ ) & $40(35.4 \%)$ & & $0.9 \pm 2.1$ & & & 2.9 & 0.162 & $1.5 \pm 2.7$ & & $1.2 \pm 2.6$ & \\
\hline No information ( $n=72)$ & $24(33.4 \%)$ & 0.874 & $0.6 \pm 1.8$ & 0.271 & & & 0.162 & $1.1 \pm 2.4$ & 0.299 & $1.1 \pm 2.6$ & 0.598 \\
\hline Anxiety $(n=77)$ & $36(46.7 \%)$ & & $1.1 \pm 2.3$ & & 2.0 & 3.1 & & $1.8 \pm 2.9$ & & $1.6 \pm 2.9$ & \\
\hline No anxiety $(n=108)$ & $28(25.9 \%)$ & $0.005^{*}$ & $0.5 \pm 1.8$ & $0.004^{*}$ & $1.3 \pm 2$ & & $0.043^{*}$ & $1.0 \pm 2.3$ & $0.028^{*}$ & $0.8 \pm 2.2$ & $0.028^{*}$ \\
\hline Pain $(n=111)$ & $47(42.3 \%)$ & & $1.1 \pm 2.3$ & & 2.1 & 3.2 & & $1.7 \pm 2.8$ & & $1.5 \pm 2.8$ & \\
\hline No pain $(n=74)$ & $17(23.0 \%)$ & $0.007^{*}$ & $0.4 \pm 1.5$ & $0.014^{*}$ & & & $0.002^{*}$ & $0.8 \pm 2.1$ & $0.005^{*}$ & $0.6 \pm 2.0$ & $0.002^{*}$ \\
\hline $\begin{array}{l}\text { *Significant correlations ( } \mathrm{p}<0.05 \\
\text { of positioning on examination ta } \\
\text { at the time of cystoscope remove } \\
\text { at the time of rectal catheter inse } \\
\text { procedure. SD: standard deviatio }\end{array}$ & $\begin{array}{l}\text { : number and pe } \\
\mathrm{e} \text {; insertion: level }\end{array}$ & $\begin{array}{l}\text { percentage of } \\
\text { el of embarraa }\end{array}$ & atients experiencins & barr & sment dur & ig the prc & cedure; tal & $\begin{array}{l}\text { : Level of embarr } \\
\text { n; removal: level } \\
\text { rtion; rectal: level }\end{array}$ & rassment on $n$ & $\begin{array}{l}\text { numerical rating sc } \\
\text { sment on numerica } \\
\text { sment on numerica }\end{array}$ & $\begin{array}{l}\text { at the tim } \\
\text { ating scale } \\
\text { ting scale } \\
\text { fore the }\end{array}$ \\
\hline
\end{tabular}

communication should be continued throughout the procedure, as patients are awake during cystoscopy and UDS. ${ }^{30}$ It is also important to point out that patients undergoing repeat procedures usually do not report lower levels of anxiety, pain, or embarrassment, and should also receive complete information with attentive listening.

The present study is, however, limited on several fronts, and the conclusions should be considered with caution. Since we did not use any local anesthesia during cystoscopies, the present results may be difficult to generalize. Moreover, voluntary participation and retrospective recall of patients represent important biases that should be considered in interpreting our results. Furthermore, the study was not specifically designed to assess the role of information in patient perception, and the quality of information provided was only ascertained through auto-administered questionnaires. Thus, we advocate further 
Biardeau et al.

investigations to draw conclusions on the influence of delivered information and communication on anxiety, pain, and embarrassment associated with cystoscopy and UDS.

\section{Conclusion}

The present study highlights strong correlations between anxiety, pain, and embarrassment reported by patients before and during cystoscopy or UDS and demonstrates the major impact of gender and age on patient experience. Interestingly, information provided before cystoscopy was demonstrated to have a negative impact on patient perception of anxiety. This association, albeit in accordance with recent publications, should be specifically assessed through further clinical trials.

Competing interests: Dr. Lam has participated in clinical trials for Medtronic and Coloplast. Dr. Campeau has been an advisor and speaker for Astellas and Pfizer; has received payment from Boston Scientific; and has received grants/honoraria from Allergan, Astellas, and Pfizer. Dr. Corcos has been an advisor for Allergan, Astellas, and Pfizer. Dr. Biardeau reports no competing personal or financial interests.

Acknowledgement: Thanks are due to Pr. Rene Yiou for his assistance in questionnaire development.

This paper has been peer-reviewed.

\section{References}

1. Yiou R, Audureau E, Loche $C-M$, et al. Comprehensive evaluation of embarrassment and pain associated with invasive urodynamics. Neurourol Urodyn 2015;34:156-60. https://doi.org/10.1002/nau.22521

2. Greenstein $A$, Greenstein I, Senderovich $S$, et al. Is diagnostic cystoscopy painful? Analysis of 1320 consecutive procedures. Int Braz J Urol 2014;40:533-8. https://doi.org/10.1590/S1677-5538. IBJU.2014.04.13

3. Yerlikaya G, Laml T, Elenskaia $K$, et al. Pain perception during outpatient cystoscopy: A prospective, controlled study. Eur J Obstet Gynecol Reprod Biol 2014;173:101-5. https://doi.org/10.1016/i. ejogrb.2013.11.007

4. Stav K, Leibovici D, Goren E, et al. Adverse effects of cystoscopy and its impact on patients' quality of life and sexual performance. Isr Med Assoc J 2004;6:474-8.

5. Ellerkmann RM, Dunn JS, McBride AW, et al. A comparison of anticipated pain before and pain rating after the procedure in patients who undergo cystourethroscopy. Am I Obstet Gynecol 2003;189:66-9. https://doi.org/10.1067/mob.2003.377

6. Yeung JY, Eschenbacher MA, Pauls RN. Pain and embarrassment associated with urodynamic testing in women. Int Urogynecol J 2014;25:645-50. https://doi.org/10.1007/s00192-013-2261-1

7. Scarpero HM, Padmanabhan $P$, Xue $X$, et al. Patient perception of videourodynamic testing: A questionnairebased study. J Urol 2005;173:555-9. https://doi.org/10.1097/01.ju.0000149968.60938.c0

8. Yokoyama T, Nozaki $\mathrm{K}$, Nose $\mathrm{H}$, et al. Tolerability and morbidity of urodynamic testing: A questionnairebased study. Urology 2005;66:74-6. https://doi.org/10.1016/i.urology.2005.01.027

9. Ellerkmann RM, McBride AW, Dunn JS, et al. A comparison of anticipatory and post-procedure pain perception in patients who undergo urodynamic procedures. Am J Obstet Gynecol 2004;190:1034-8. https://doi.org/10.1016/i.ajog.2003.11.006
10. Stein $M$, Lubetkin $D$, Taub $H C$, et al. The effects of intraurethral lidocaine anesthetic and patient anxiety on pain perception during cystoscopy. J Urol 1994;151:1518-21.

11. Goldfischer ER, Cromie WJ, Karrison TG, et al. Randomized, prospective, double-blind study of the effects on pain perception of lidocaine jelly vs. plain lubricant during outpatient rigid cystoscopy. J Urol 1997; 157:904. https://doi.org/10.1016/S0022-5347(01)65292-3

12. Greenstein A, Bar-Yosef $Y$, Chen J, et al. Does information provided to men before a urodynamic study affect their expectation of pain? BJU Int 2005;96:1307-9. https://doi.org/10.1111/j.1464410X.2005.05828.x

13. Seklehner $S$, Remzi $M$, Faikovic $H$, et al. Prospective multi-institutional study analyzing pain perception of flexible and rigid cystoscopy in men. Urology 2015;85:737-41. https://doi.org/10.1016/i.urology.2015.01.007

14. Seklehner $S$, Saratlija-Novakovic $Z$, Skopek $M$, et al. Prospective, multi-institutional pain assessment of 150 women undergoing diagnostic cystoscopy. Minerva Urol Nefrol 2016;68:417-23.

15. Aaronson DS, Walsh TJ, Smith JF, et al. Meta-analysis: Does lidocaine gel before flexible cystoscopy provide pain relief? BJU Int 2009;104:506-9; discussion 509-10. https://doi.org/10.1111/j.1464410X.2009.08417.x

16. Komiya $A$, Endo $T$, Kobayashi $M$, et al. Oral analgesia by non-steroidal anti-inflammatory drug zaltoprofen to manage cystoscopy-related pain: A prospective study. Int J Urol 2009;16: 874-80. https://doi.org/10.1111/i.1442-2042.2009.02384.x

17. Calleary JG, Masood J, Van-Mallaerts R, et al. Nitrous oxide inhalation to improve patient acceptance and reduce procedure related pain of flexible cystoscopy for men younger than 55 years. J Urol 2007;178:1848; discussion 188. https://doi.org/10.1016/i.juro.2007.03.036

18. Zhang Z-S, Wang X-L, Zeng S-X, et al. Pressure makes pleasure: A preliminary study of increasing irrigation pressure of flexible cystoscopy improves male patient comfort by an easy way. J Endourol 2015;29:13615. https://doi.org/10.1089/end.2014.0714

19. Gunendran T, Briggs RH, Wemyss-Holden GD, et al. Does increasing hydrostatic pressure ("bag squeeze") during flexible cystoscopy improve patient comfort: A randomized, controlled study. Urology 2008;72:2558; discussion 258-9. https://doi.org/10.1016/i.urology.2008.02.072

20. Zhang Z-S, Wang X-L, XU C-L, et al. Music reduces panic: an initial study of listening to preferred music improves male patient discomfort and anxiety during flexible cystoscopy. J Endourol 2014;28:739-44. https://doi.org/10.1089/end.2013.0705

21. Yeo JK, Cho DY, Oh MM, et al. Listening to music during cystoscopy decreases anxiety, pain, and dissatisfaction in patients: A pilot randomized, controlled trial. J Endourol 2013;27:459-62. htrps://doi.org/10.1089/end.2012.0222

22. Zhang $Z$, Tang $L$, Wang $X$, et al. Seeing is believing: A randomized, controlled study from China of realtime visualization of flexible cystoscopy to improve male patient comfort. J Endourol 2011;25:1343-6. https://doi.org/10.1089/end.2011.0084

23. Patel AR, Jones IS, Babineau D. Impact of real-ime visualization of cystoscopy findings on procedural pain in female patients. J Endourol 2008;22:2695-8. https://doi.org/10.1089/end.2008.0076

24. Kesari D, Kovisman V, Cytron $S$, et al. Effects on pain and anxiety of patients viewing their cystoscopy in addition to a detailed explanation: A controlled study. BJU Int 2003;92:751-2. https://doi.org/10.1046/i.1464-410X.2003.04477.x

25. Walker MR, Kallingal GJS, Musser JE, et al. Treatment efficacy of virtual reality distraction in the reduction of pain and anxiety during cystoscopy. Mil Med 2014;179:891-6. https://doi.org/10.7205/ MILMED-D-13-00343

26. Richter M, Eck J, Straube T, et al. Do words hurt? Brain activation during the processing of pain-related words. Pain 2010;148:198-205. https://doi.org/10.1016/i.pain.2009.08.009

27. Lang EV, Hatsiopoulou 0, Koch T, et al. Can words hurt? Patient-provider interactions during invasive procedures. Pain 2005;114:303-9. https://doi.org/10.1016/i.pain.2004.12.028

28. Eberhardt J, van Wersch $A$, van $S$ chaik $P$, et al. Information, social support. and anxiety before gastrointestinal endoscopy. Br J Health Psychol 2006;11:551-9. https://doi.org/10.1348/135910705X72514

29. Felley C, Perneger TV, Goulet I, et al. Combined written and oral information prior to gastrointestinal endoscopy compared with oral information alone: A randomized trial. BMC Gastroenterol 2008;8:22. https://doi.org/10.1186/1471-230X-8-22

30. Morgan M, Dodds W, Wolfe C, et al. Women's views and experiences of outpatient hysteroscopy: Implications for a patient-centred service. Nurs Health Sci 2004;6:315-20. https://doi.org/10.1111/ j.1442-2018.2004.00202.x

Correspondence: Dr. Jacques Corcos, Department of Urology, Jewish General Hospital, Montreal, QC, Canada; jcorcosmd@yahoo.com 